\title{
CFTR and Anoctamin 1 (ANO1) contribute to cAMP amplified exocytosis and insulin secretion in human and murine pancreatic beta-cells
}

\author{
Anna Edlund ${ }^{1}$, Jonathan LS Esguerra', Anna Wendt ${ }^{1}$, Malin Flodström-Tullberg ${ }^{2 \dagger}$ and Lena Eliasson $^{1^{*}+}$
}

\begin{abstract}
Background: Mutations in the cystic fibrosis transmembrane conductance regulator (CFTR) gene lead to the disease cystic fibrosis (CF). Although patients with CF often have disturbances in glucose metabolism including impaired insulin release, no previous studies have tested the hypothesis that CFTR has a biological function in pancreatic beta-cells.

Methods: Experiments were performed on islets and single beta-cells from human donors and NMRI-mice. Detection of CFTR was investigated using PCR and confocal microscopy. Effects on insulin secretion were measured with radioimmunoassay (RIA). The patch-clamp technique was used to measure ion channel currents and calcium-dependent exocytosis (as changes in membrane capacitance) on single cells with high temporal resolution. Analysis of ultrastructure was done on transmission electron microscopy (TEM) images.

Results: We detected the presence of CFTR and measured a small CFTR conductance in both human and mouse beta-cells. The augmentation of insulin secretion at $16.7 \mathrm{mM}$ glucose by activation of CFTR by CAMP (forskolin (FSK) or GLP-1) was significantly inhibited when CFTR antagonists (GlyH-101 and/or CFTRinh-172) were added. Likewise, capacitance measurements demonstrated reduced cAMP-dependent exocytosis upon CFTR-inhibition, concomitant with a decreased number of docked insulin granules. Finally, our studies demonstrate that CFTR act upstream of the chloride channel Anoctamin 1 (ANO1; TMEM16A) in the regulation of CAMP- and glucose-stimulated insulin secretion.

Conclusion: Our work demonstrates a novel function for CFTR as a regulator of pancreatic beta-cell insulin secretion and exocytosis, and put forward a role for CFTR as regulator of ANO1 and downstream priming of insulin granules prior to fusion and release of insulin. The pronounced regulatory effect of CFTR on insulin secretion is consistent with impaired insulin secretion in patients with CF.
\end{abstract}

Keywords: CFTR, Cystic Fibrosis, Diabetes, Insulin secretion, Islet of Langerhans, Beta-cell, Exocytosis

\section{Background}

The cystic fibrosis transmembrane conductance regulator (CFTR) is a cAMP-regulated chloride channel that belongs to the family of ATP-binding cassette (ABC)-transporters [1]. As many other $\mathrm{ABC}$-transporters, CFTR contains two membrane spanning domains (MSDs) and two nucleotide binding domains (NBDs) that interact with ATP. In addition, CFTR has a regulatory domain (R)

\footnotetext{
* Correspondence: lena.eliasson@med.lu.se

${ }^{\dagger}$ Equal contributors

'Unit of Islet Cell Exocytosis, Lund University Diabetes Centre, Department Clinical Sciences in Malmö, Lund University, Clinical Research Centre, SUS

Malmö, Jan Waldenströms gata 35, SE 20502 Malmö, Sweden

Full list of author information is available at the end of the article
}

that contains several phosphorylation sites. The chloride selective pore of the channel is formed by the MSDs, whereas the other domains control channel gating [1]. Apart from being an anion channel, CFTR has been suggested to act as a regulator of other proteins and ion channels [2] in similarity with other members of the family of $\mathrm{ABC}$-transporters, such as the sulfonylurea receptor (SUR1).

CFTR is primarily present in epithelial cells in airways, intestine and in cells with exocrine functions. Mutations in the gene encoding the channel protein complex ( $c f t r)$ cause the autosomal recessive disease cystic fibrosis $(\mathrm{CF})$. In patients with CF the defective 
chloride transport through CFTR leads to production of thick viscous mucus caused by a disturbed ion and water transport across epithelial membranes. The aberrant secretory functions cause obstruction of the distal airways and intestine, pancreatitis and malabsorption [3].

With increasing lifespan many CF patients develop cystic fibrosis-related diabetes (CFRD). The mean age of CFRD onset is around 20 years and the prevalence varies between 30 to $50 \%$ depending on the population studied [4-7]. Despite an increased awareness of the clinical impact of CFRD surprisingly little is known about its etiopathogenesis. CFRD is associated with exocrine pancreatic insufficiency caused by duct obstruction and fibrosis, but not all patients with pancreatic insufficiency develop diabetes [8,9]. It has been suggested that the endocrine problem is, at least in part, mechanical $[4,9]$. Abnormalities in the islet architecture and beta-cell loss have been observed while alpha- and delta-cell mass have remained intact or even increased [10-13]. However, observations showing that CFRD often correlates with insulin deficiency and/or a significant lower first-phase insulin secretion (for example, in $[8,9,14,15])$, clearly indicate that other, beta-cell intrinsic factors, may play a causative role in CFRD. Moreover, many CF patients, also those without CFRD, have normal fasting plasma glucose levels, but suffer from postprandial hyperglycemia indicating that the beta-cells fail to respond upon increased insulin demand. A recent pilot study [16] performed on five CFRD patients with the G551D mutation having reduced/absent acute insulin response is in support of an insulin secretion defect in CFRD. One-month treatment with Ivacaftor, a newly developed CFTR potentiator, increased the insulin response to oral glucose in four out of the five patients. On a cellular level, data from insulin secreting HIT-cells support a role for an ATP-sensitive and cAMP-activated current in insulin secreting cells [17]. Boom et al. revealed that CFTR mRNA and protein are expressed by both alpha- and beta-cells in rats [18], but did not investigate the physiological importance of CFTR for the functions of these cells. In the present study, we have used murine and human pancreatic islets and single beta-cells to test the hypothesis that active CFTR is present in beta-cells and essential in regulating insulin secretion.

\section{Methods}

\section{Ethical statement}

Animal procedures were approved by the local ethics committee for use of laboratory animals in Malmö, Sweden. Human islet isolation from deceased donors and experimental protocols were approved by the ethics committee in Uppsala and Malmö, Sweden.

\section{Islet isolation and cell culture}

Islets from 43 non-diabetic human donors (F/M 18/25, age $59 \pm 1.3$, body mass index (BMI) $25.5 \pm 0.5 \mathrm{~kg} / \mathrm{m}^{2}$, HbA1c $5.7 \pm 0.04$, days in culture $4.1 \pm 0.3$ ) were used for secretion measurements, patch-clamp experiments, qPCR and immunohistochemistry. For these experiments islets were hand-picked to ensure high purity. Human islets were provided by the Nordic Network for Clinical Islet Transplantation (Uppsala, Sweden) through the LUDC Human Tissue Laboratory. Female NMRI mice (Bolmholtgaard, Ry, Denmark) were sacrificed by cervical dislocation and islets were isolated by collagenase digestion and hand-picked prior to experiments. For patch-clamp measurements, human and mouse islets were dispersed into single cells as previously described [19].

\section{mRNA expression measured with RT-qPCR}

Total RNA from human and mouse islets were prepared as described [20]. CFTR mRNA expression was measured by RT-qPCR using primers and probes from Taqman mRNA assays (Life Technologies, California, USA). Human CFTR: Hs00357011_m1 expression was normalized against human HPRT1: 4333768 F, while mouse CFTR: Mm00445197_m1 expression was normalized against mouse HPRT1: Mm00446968. RT-qPCR runs were performed for individual batches of human $(N=5)$ and mouse $(N=5)$ islets in triplicate wells of 384-well plate on a 7900 HT RT-PCR system (Applied Biosystems, California, USA).

\section{Immunocytochemistry}

Human or mouse single cells were fixed and stained as described elsewhere [21]. Primary antibodies; Mouse monoclonal anti-CFTR (MATG-1061, RD-Biotech, France), Guinea pig monoclonal anti-insulin (Linco, Billerica, MA, USA), Guinea pig monoclonal anti-insulin (EuroDiagnostica, Malmö, Sweden) and rabbit polyclonal anti-Stx1A (Synaptic Systems, Goettingen, Germany). Secondary antibodies; guinea pig conjugated to $\mathrm{Cy} 2$, mouse conjugated to $\mathrm{Cy} 3$, guinea pig and rabbit conjugated to Cy5 (all from Jackson, UK). Immunofluorescence was detected with a confocal microscope (META 510, Zeiss, Germany) and unspecific binding of the secondary antibodies was excluded by parallel experiments in the absence of the primary antibodies. Localization of CFTR was analyzed as described elsewhere [22]. In short, the ratio between the mean fluorescent intensity in the plasma membrane region $\left(\mathrm{P}_{1}\right)$ and the cytosolic region $\left(\mathrm{P}_{2}\right)$ was measured using ZEN software (Zeiss, Jena, Germany). Pixel by pixel co-localization analysis was also performed using Zen software. The same laser setting was retained between experiments enabling comparison of experiments performed at different occasions. 


\section{Patch-clamp recordings}

EPC10 amplifier and 8.80 pulse software (HEKA, Lambrecht/ Pfalz, Germany) was used to evoke and record whole-cell currents and changes in membrane capacitance on single mouse and human islet cells as described [19]. Current and capacitance measurements were performed at RT and 32 to $33^{\circ} \mathrm{C}$, respectively. Extracellular solution contained: $118 \mathrm{mM} \mathrm{NaCl}, 20 \mathrm{mM}$ TEACl, $5.6 \mathrm{mM} \mathrm{KCl}, 2.6 \mathrm{mM}$ $\mathrm{CaCl}_{2}, 1.2 \mathrm{mM} \mathrm{MgCl}$, 5 mM HEPES, 3 (current measurements)/5 (capacitance measurements) mM D-glucose $\mathrm{pH}$ 7.4 (NaOH), supplemented with $10 \mu \mathrm{M}$ FSK, $200 \mu \mathrm{M}$ 4,4'-Diisothiocyano-2,2'-stilbenedisulfonic acid (DIDS), $10 \mu \mathrm{M} \mathrm{CFTR}_{\text {inh }}-172$ (Sigma Aldrich, Sweden), $25 \mu \mathrm{M}$ (current measurements) or $40 \mu \mathrm{M}$ (capacitance measurements) GlyH-101 (Calbiochem, USA) [23,24] and $50 \mu \mathrm{M}$ T16Ainh-AO1 (gift from A.S. Verkman, Department of Medicine, UCSF School of Medicine) as indicated. The intracellular solution contained: $125 \mathrm{mM}$ $\mathrm{CsOH}, 125 \mathrm{mM}$ Glutamate, $10 \mathrm{mM} \mathrm{CsCl}, 10 \mathrm{mM} \mathrm{NaCl}$, $1 \mathrm{mM} \mathrm{MgCl} 2,3 \mathrm{mM} \mathrm{Mg-ATP,} 4 \mathrm{mM}$ EGTA (current measurement)/0.05 mM EGTA (capacitance measurement), $5 \mathrm{mM}$ HEPES and $0.1 \mathrm{mM}$ cAMP (capacitance measurements) ( $\mathrm{pH} 7.15$ with $\mathrm{CsOH}$ ).

\section{Insulin secretion measurements}

Insulin secretion was measured in static batch incubations described previously [25]. Briefly islets were preincubated in $1 \mathrm{mM}$ glucose for 30 minutes followed by $1 \mathrm{~h}$ incubation in extracellular solution with variable glucose concentration. Incubation was $15 \mathrm{~min}$ when $50 \mathrm{mM} \mathrm{KCl}$ was used as stimulator. The extracellular solution was supplemented with $10 \mu \mathrm{M}$ FSK, $0.1 \mu \mathrm{M}$ GLP-1 (Bachem, Weil am Rhein, Switzerland), $100 \mu \mathrm{M}$ Tolbutamide (Sigma Aldrich, Stockholm, Sweden), $200 \mu \mathrm{M}$ DIDS, $50 \mu \mathrm{M}$ TMinh-AO1, $40 \mu \mathrm{M}$ CFTRinh172 and/or $50 \mu \mathrm{M}$ GlyH-101 as indicated. Insulin secretion was measured using radioimmunoassay kit (mouse: Linco Research Inc.,; human: Millipore, Billerica, MA, USA).

\section{Transmission electron microscopy}

Islets were collected after insulin secretion assay and prepared for electron microscopy, examined and analyzed as previously described [26]. The granule volume density $\left(\mathrm{N}_{\mathrm{v}}\right)$ and surface density $\left(\mathrm{N}_{\mathrm{s}}\right)$ were calculated using in-house software programmed in MatLab.

\section{Statistical analysis}

Data are presented as mean \pm SEM of $\mathrm{N}$ number of individuals or independent experiments and number of cells or biological replicates. Statistical significance was calculated using ANOVA or Student's $t$ test and $P<0.05$ was considered significant.

\section{Results}

CFTR-antagonists inhibit insulin secretion and an ATP-sensitive and CAMP-dependent current in mouse and human beta-cells

To investigate if CFTR affects beta-cell function, the influence of CFTR on insulin secretion was measured from isolated human and mouse pancreatic islets subjected to glucose-induced insulin secretion assays. In human islets, glucose caused a dose-dependent increase in insulin secretion that was further enhanced by the cAMP-increasing agent FSK. The stimulatory action of FSK at $16.7 \mathrm{mM}$ glucose was significantly reduced in the presence of the CFTR-antagonist GlyH-101 (Figure 1A). Next we investigated the effect of a more physiological elevator of cAMP, the incretin hormone GLP-1. Like FSK, GLP-1 enhanced insulin secretion at $16.7 \mathrm{mM}$ glucose in human islets, an effect that was completely inhibited by $\mathrm{GlyH}-101$ (Figure 1B). In mouse islets, both FSK and GLP-1 amplified insulin secretion stimulated by glucose was reduced in the presence of GlyH-101. Moreover, CFTRinh-172, another antagonist against CFTR, also decreased both FSK and GLP-1 enhanced insulin secretion (Figures 1C, D). Both inhibitors are specific for CFTR, and whereas CFTRinh-172 binds to the intracellular domain of CFTR [23] and thereby closes the channel, GlyH-101 is an open-channel blocker [24]. It was confirmed that the antagonists had no significant effect on insulin secretion at $1 \mathrm{mM}$ glucose (Figure 1E) or in presence of $16.7 \mathrm{mM}$ glucose in the absence of FSK or GLP-1 (Figure 1F). There was, though, a tendency towards a reduction in insulin secretion by GlyH-101 in the presence of $16.7 \mathrm{mM}$ glucose alone in the human islets. This might be due to a higher increase in cAMP caused by glucose. It has been demonstrated that glucose increases cAMP levels in both mouse [27] and human [28] beta-cells. However, why the increase in cAMP generated by glucose might be higher in human islets is not clear but could be explained by the higher number of alpha-cells in the human islets [29,30]. cAMP is a potent second messenger that promotes insulin secretion by several mechanisms $[19,31]$. Here we establish that CFTR has an essential and complementary function in cAMPamplified insulin secretion. In parallel to these findings, we found expression of CFTR mRNA (data not shown) and CFTR protein in both human and mouse islets (Figure 1G).

The presence of active CFTR channels in pancreatic beta-cells was investigated on single cells using the patchclamp technique in the standard whole-cell configuration. The pipette solution contained sodium and calcium ions in order to determine the cell-type by sodium channel inactivation properties [32]. A voltage-ramp protocol from $-100 \mathrm{mV}$ to $+100 \mathrm{mV}$ was applied before and every fourth minute after the addition of FSK $(10 \mu \mathrm{M})$ 


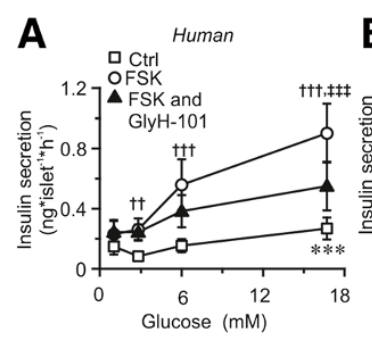

F Mouse

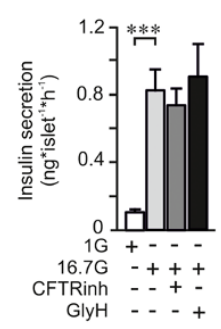

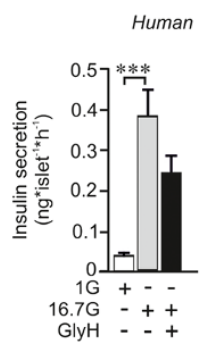

B Human C
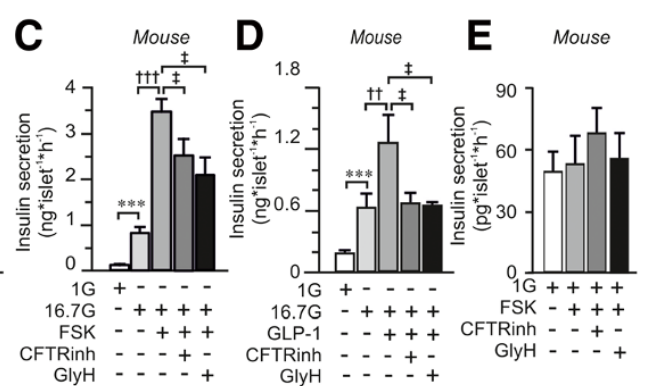

GlyH
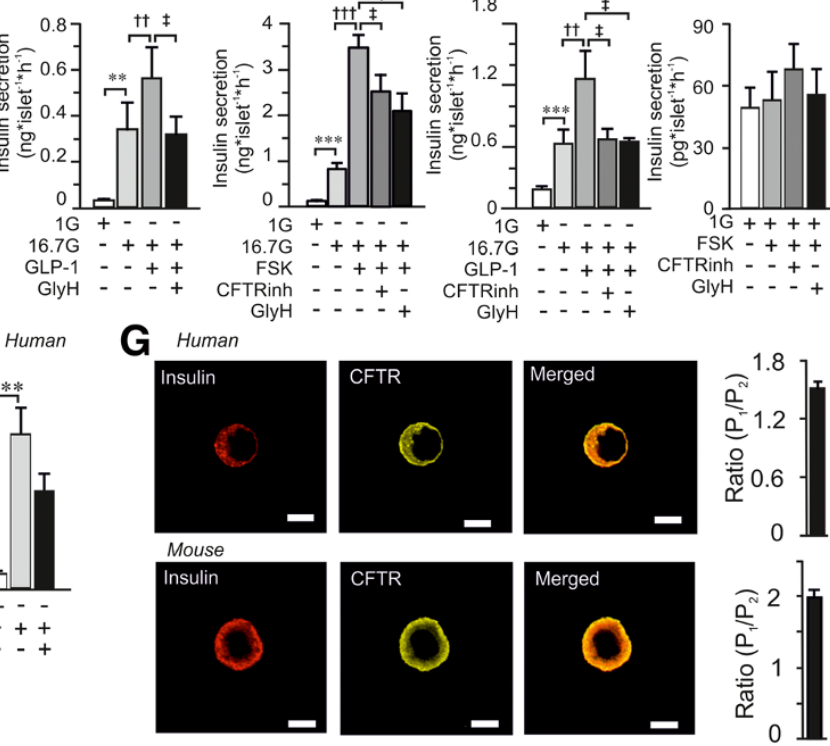

Figure 1 Effect of CFTR inhibition on insulin secretion measured in isolated human and mouse pancreatic islets. (A) Insulin secretion from human islets at different glucose in the absence or presence of forskolin (FSK) and GlyH-101 (GlyH) as indicated ( $n=42$ to $45, N=11$ ). (B) Insulin secretion from human islets at $1 \mathrm{mM}$ glucose (1G) or $16.7 \mathrm{mM}$ glucose (16.7G) in the absence and presence of GLP-1 and GlyH-101 as indicated ( $\mathrm{n}=17$ to $19, \mathrm{~N}=5$ ). (C-D) Insulin secretion from mouse islets at $1 \mathrm{mM}$ glucose (1G) or $16.7 \mathrm{mM}$ glucose (16.7G) in the absence or presence of FSK, GLP-1, CFTRinh-172 (CFTRinh) and GlyH-101 (GlyH) as indicated ( $n=12$ to 21, $N=4$ to 9). (E) Insulin secretion from mouse islets at $1 \mathrm{mM}$ glucose (1G) in the absence or presence of FSK and inhibitors as indicated $(n=9-12, N=4)$. (F) Insulin secretion from mouse (left) and human (right) islets in the absence of FSK to demonstrate the lack of effect of the inhibitors (mouse: $n=10, N=5$; human $n=12, N=3$ ). (G) Localization of CFTR (yellow) and insulin (red) in fixed single islet cells (left) from human (top) and mouse (bottom), detected using confocal immunocytochemistry. Scale bar $5 \mu \mathrm{m}$. Images are representative of 37 beta-cells from three human donors and 23 beta-cells from three mice. Ratio of the fraction of CFTR (right) in the plasma membrane region $\left(P_{1}\right)$ as compared to the cytosolic region $\left(P_{2}\right)$ for human (top) and mouse (bottom) beta-cells. Data are presented as mean \pm SEM. ${ }^{* * *} P<0.00116 .7 \mathrm{G}$ vs $1 \mathrm{G},{ }^{+\dagger} P<0.01$ FSK or GLP-1 vs respective $\mathrm{G}$ alone, ${ }^{+\dagger+} P<0.001$ FSK vs respective $\mathrm{G}$ alone and ${ }^{\ddagger} P<0.05$ CFTRinh or GlyH vs $16.7 \mathrm{G}$ and FSK alone, ${ }^{\ddagger \neq \ddagger} p<0.001 \mathrm{GlyH}$ vs $16.7 \mathrm{G}$ and FSK alone.

until steady state was achieved (Figure 2). In the absence of FSK the current flow was minimal, whereas the increase in intracellular cAMP induced by FSK activated a nonlinear outward rectifying current. In human and mouse beta-cells, the cAMP-activated current was significantly inhibited by the CFTR-inhibitors (Figure 2A-D). The current inhibited by CFTR-inhibitors (CFTR-dependent) constitute $47 \pm 15 \%(n=7)$ and $57 \pm 7 \%(n=10)$ of the FSK-activated current at negative potentials, in human and mouse beta-cells, respectively.

In addition to the ion channel function, CFTR has been attributed a role as regulator of other ion channels and proteins, such as other chloride channels $[2,33]$. To investigate the possibility that CFTR regulates the function of other chloride channels we used the non-specific chloride channel blocker DIDS that blocks a wide variety of chloride channels, while CFTR is insensitive to this antagonist [34,35]. The cAMP-stimulated current, in human and mouse beta-cells, was significantly reduced by DIDS (Figure 2E, F). The presence of active CFTR channels was proven by a significant reduction in current conductance in the simultaneous presence of GlyH-101 and DIDS as compared with DIDS alone (Figure 2E, F). The DIDS-sensitive component constituted $38 \pm 10 \%$ and CFTR $37 \pm 15 \%(n=5)$ of the FSK-activated current at negative potentials $(-100$ to $-50 \mathrm{mV})$ in human beta-cells. In the mouse, the DIDS-sensitive current was $41 \pm 12 \%$ and CFTR $29 \pm 9 \%(n=8)$ of the FSK-activated current. From these measurements the CFTR conductance was estimated to be $2.8 \pm 0.6 \mathrm{pS} / \mathrm{pF}$ in human $(\mathrm{n}=5 ; \mathrm{N}=3)$ and $12 \pm 4.0 \mathrm{pS} / \mathrm{pF}$ in mouse $(\mathrm{n}=8 ; \mathrm{N}=5)$ beta-cells at negative potentials $(-100 \mathrm{mV}$ to $-50 \mathrm{mV})$. Taken together these data indicate that 1) the cAMP-induced chloride current has one DIDS-sensitive component and one part sensitive to CFTR inhibition, 2) the current through CFTR in beta-cells is small, and 3) CFTR likely acts as a regulator of DIDS-sensitive chloride channel(s).

\section{CFTR likely regulates the chloride channel Anoctamin 1 (ANO1)}

The suggestion that CFTR can act as a regulator upstream of other chloride channels involved in the regulation of insulin release was verified through the investigation of the combined effect of DIDS and GlyH-101 on insulin 

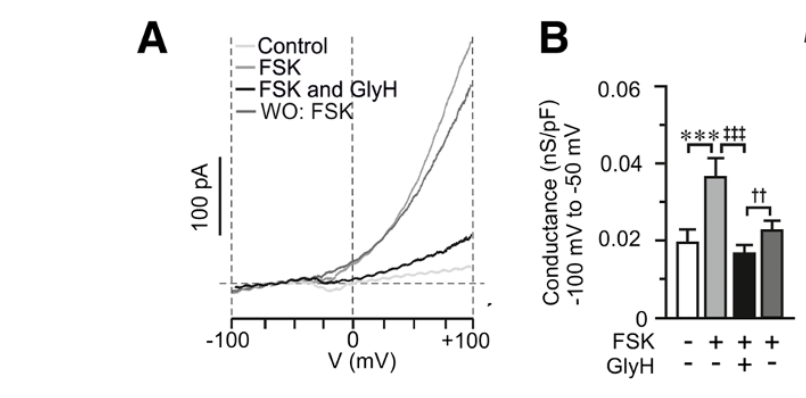

Human
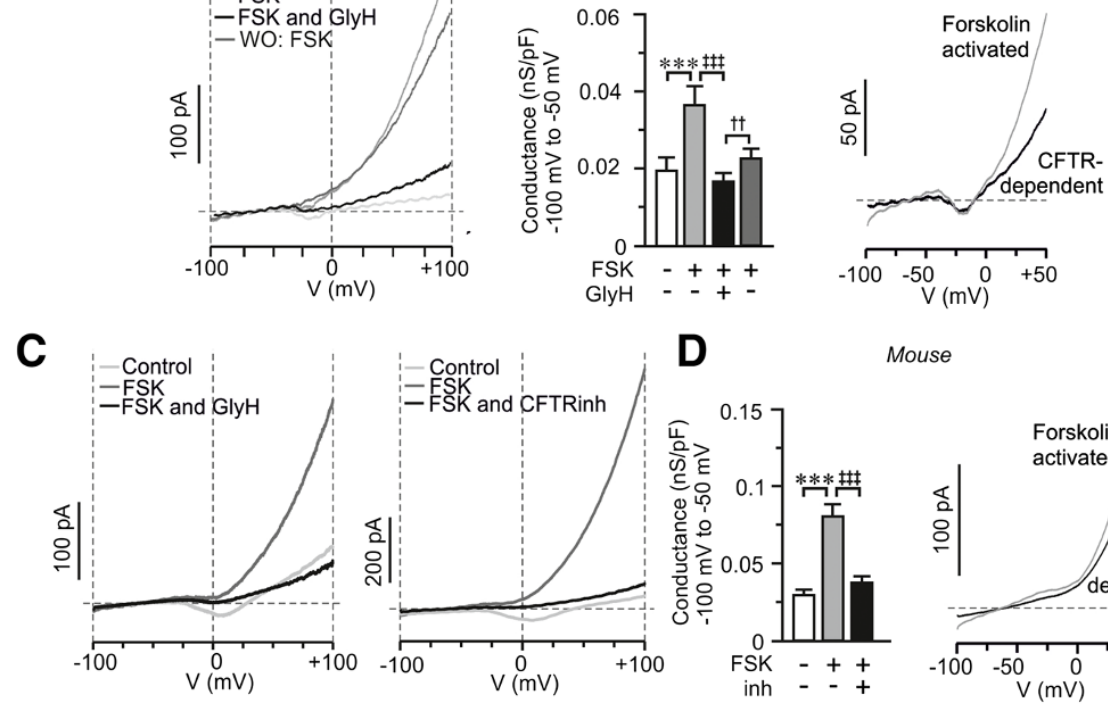

E
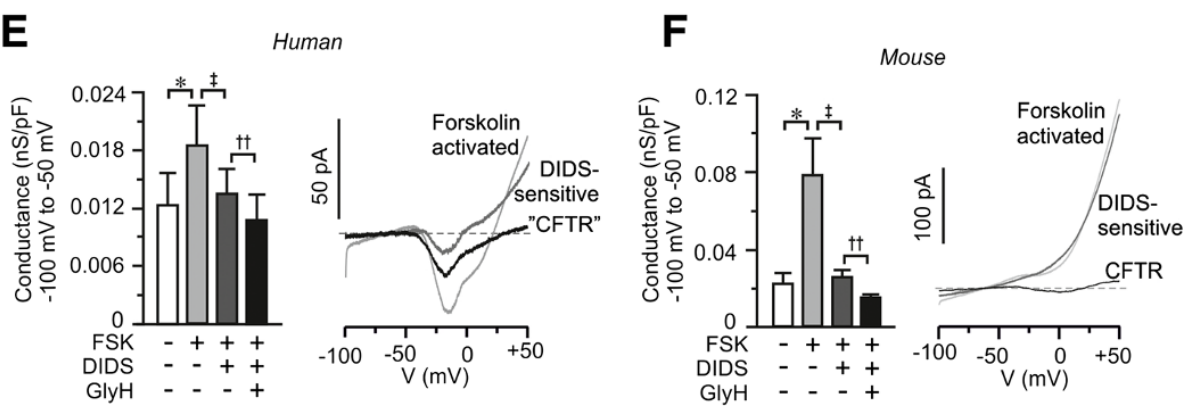

Figure 2 cAMP-activated chloride currents in human and mouse beta-cells. (A) Currents measured in a single human beta-cell after stimulation with voltage ramps in the absence (Ctrl, light gray) and presence of forskolin (FSK; gray), in the simultaneous presence of FSK and GlyH-101 (FSK and GlyH; black) and after wash-out of GlyH-101 to recover the FSK-activated current (WO: FSK; dark gray). Current ramps were applied before and every fourth minute after the application of FSK until a steady state was achieved. (B) Bar graph of the membrane conductance at negative voltages (left; $n=7$ to $17, N=3$ ) and graph of calculated FSK-activated and CFTR-dependent current (right; Mean of $n=7$ cells) from data in A. (C) Same as in A, but experiments where performed on mouse beta-cell. GlyH-101 (GlyH: black trace) and CFTRinh-172 (CFTRinh, black) was added to the left and right, as indicated. (D) As in B, but membrane conductance (left) was calculated from data in C ( $n=10$ to 17, $N=8$ ). The mean result was combined for both CFTR-inhibitors (Inh). The calculated FSK-activated and CFTR-dependent current to the right is a mean from 10 cells. (E) As in A, but the effect of 4,4'-Diisothiocyano-2,2'-stilbenedisulfonic acid (DIDS) was investigated ( $n=6, N=2)$. Calculated FSK-activated, DIDS-sensitive and CFTR-currents shown to the right are mean of $n=5$ cells. (F) Same as in $E$, but the membrane conductance (left) was calculated from measurements in mouse beta-cells $(n=9, N=6)$ and the calculated current to the right is the mean from $n=8$ cells. Data are presented as mean \pm SEM. ${ }^{*} P<0.05,{ }^{* * *} P<0.005,{ }^{\ddagger} P<0.05,{ }^{\ddagger \neq \neq} p<0.005,{ }^{\dagger} P<0.01$ and ${ }^{\dagger+} P<0.01$.

secretion. The experiment was conducted in the presence of tolbutamide to circumvent that DIDS might affect the ATP-dependent potassium channel [36]. At high concentrations tolbutamide can inhibit CFTR currents [37], but at the concentration used here $(100 \mu \mathrm{M})$ the major influence is on the closure of the ATP-dependent potassium channel. This was confirmed by insulin secretion measurements showing that tolbutamide increased (rather than decreased) insulin secretion at $16.7 \mathrm{mM}$ glucose in mouse islets, while no further stimulation of insulin secretion was observed in human islets (Figure 3A, B). This is most likely due to the different sensitivity of glucose in mouse and human islets and in line with previous results $[38,39]$. In the presence of tolbutamide, GLP-1-enhanced glucose-stimulated insulin secretion was significantly reduced in the presence of DIDS (Figure 3A, B), in both mouse and human islets. The addition of GlyH-101 in the continued presence of DIDS did not further reduce the secretory response in mouse beta-cells as compared to DIDS alone (Figure 3A), suggesting that CFTR regulates a DIDS-sensitive chloride channel.

Recently, it was suggested that channels from the family of Anoctamins (ANO1-10) are controlled by CFTR [40,41]. The first member in this family, ANO1, is a voltage- and 

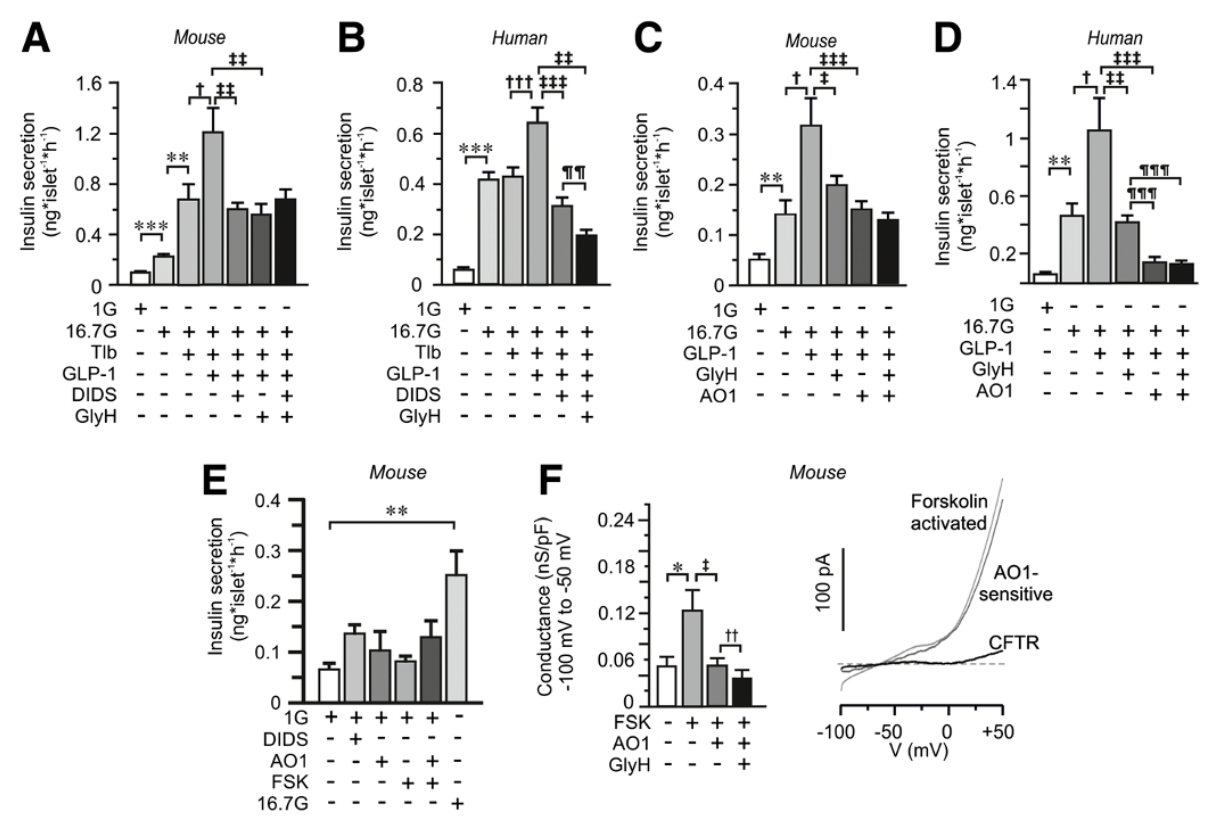

Figure 3 The combined effect of chloride channel blockers on GLP-1 enhanced GSIS. (A) Insulin secretion from mouse islets after $1 \mathrm{~h}$ incubation in $1 \mathrm{mM}$ glucose (1G), $16.7 \mathrm{mM}$ glucose (16.7G), tolbutamide (Tlb), GLP-1, DIDS- and GlyH-101 as indicated $(n=12$ to $20, N=4)$. (B) The same as in $A$, but insulin secretion was measured from human islets ( $n=20$ to $28, N=5)$. (C) As in $A$, but the impact of the anoctamin 1 inhibitor TM16Ainh-AO1 (AO1) on GLP-1 enhanced insulin secretion was investigated in mouse islets $(n=14, N=3)$. (D) As in $C$, but experiments were performed on human islets $(n=4, N=1)$. (E) As in $C$, but the effects of forskolin (FSK) and AO1 was investigated at $1 \mathrm{mM}$ glucose as

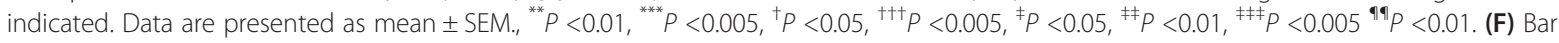
graph of membrane conductance at negative (left) membrane potentials in the absence and presence of FSK, TM16Ainh-AO1 (AO1) and GlyH-101 $(\mathrm{GlyH})(n=6, N=4)$. Calculated FSK-activated, AO1-sensitive and CFTR-currents shown to the right are mean of $n=5$ cells. Data are presented as mean \pm SEM. ${ }^{*} P<0.05,{ }^{\ddagger} P<0.05,{ }^{\ddagger \ddagger} P<0.01$.

calcium-dependent chloride channel localized in the plasma membrane that has been suggested to interact with CFTR to control chloride conductance in epithelial cells [41]. Interestingly, ANO1 gene expression has been measured in rat and human islets [42,43]. To investigate the possible combined involvement of ANO1 and CFTR in the regulation of insulin secretion we performed insulin secretion measurements in mouse and human islets in the presence or absence of specific blockers of the respective channel. Indeed, insulin secretion enhanced by GLP-1 was reduced by TM16Ainh-AO1 (AO1), a specific blocker of ANO1 [44], and in the combined presence of GlyH-101 and AO1 the reduction in GLP-1 enhanced glucosestimulated insulin secretion was not significantly different from the reduction observed after application of either of them alone (Figure 3C, D). In human islets, the inhibitory effect of AO1 was significantly more potent than GlyH101 alone, but, as in the mouse, inclusion of GlyH-101 in the simultaneous presence of $\mathrm{AO} 1$ did not cause an additive decrease in GLP-1 amplified insulin secretion at $16.7 \mathrm{mM}$ glucose (Figure 3D). It was confirmed that AO1 did not have any inhibitory effect at $1 \mathrm{mM}$ glucose (Figure 3E).

The presence of ANO1 chloride current in beta-cells was measured by patch-clamp recordings on single mouse beta-cells using the standard whole-cell mode and the ramp-protocol as used above. It was obvious that the FSK-activated current was reduced by $\mathrm{AO} 1$, and the conductance was decreased (Figure 3F). A small, but significant, further reduction in conductance was obtained in the simultaneous presence of AO1 and the CFTRinhibitor GlyH-101 (Figure 3F). The AO1-sensitive current was calculated to represent $50 \pm 10 \%$ and CFTR $30 \pm 5 \%$ of the FSK-activated current at negative potentials $(n=5)$. The CFTR conductance was estimated to $14 \pm 3 \mathrm{pS} / \mathrm{pA}(\mathrm{n}=5)$. Interestingly, these are similar to values obtained from the DIDS-experiments in Figure 2 (12 pS/PA and 29\%). This experiment demonstrates that the blockers $\mathrm{AO} 1$ and $\mathrm{GlyH}$ 101 most likely act on separate channels (Figure 3E). Hence, the lack of an additive effect on secretion (Figure 3C, D) would suggest that CFTR interacts with ANO1 in regulating insulin secretion.

\section{Inhibition of CFTR results in decreased exocytosis in mouse and human beta-cells}

We were next interested in investigating mechanisms by which CFTR and ANO1 influence insulin secretion. Insulin secretion comprises a cascade of events often referred to as the "stimulus-secretion-coupling" [45]. Briefly, glucose uptake and metabolism yields ATP, 
leading to depolarization of the plasma membrane, opening of voltage sensitive calcium channels and increased levels of intracellular calcium resulting in exocytosis of insulin granules. Theoretically, CFTR could be involved in any of these steps. Indeed, it has been suggested that an ATP-sensitive and cAMP-activated chloride current influences the membrane depolarization and electrical activity of insulin secreting cells [17]. We found that CFTRinhibition reduced insulin secretion under conditions independent of cellular metabolism and membrane depolarization (Figure 4A), suggesting a possible function of CFTR in the downstream exocytotic process. To elaborate further on this, capacitance recordings were performed on single beta-cells in the presence of ATP and cAMP in the intracellular solution. Exocytosis, evoked by a train of 10500 -ms depolarizations from $-70 \mathrm{mV}$ to $0 \mathrm{mV}$, was significantly reduced in human beta-cells pre-incubated with GlyH-101 (Figure 4B, C). The reduction in membrane capacitance increase was most prominent during the first two depolarizations reflecting rapid exocytosis of primed granules [46]. The exocytotic response in mouse beta-cells was likewise reduced after CFTR-inhibition (Figure 4D, E). Next, effects on voltage-dependent calcium currents were investigated. The current was evoked by $50-\mathrm{ms}$ depolarizations from $-70 \mathrm{mV}$ to voltages between -50 and $+50 \mathrm{mV}$ in single human or mouse beta-cells and in the presence and absence of GlyH-101 or CFTRinh-172, respectively (Figure 4F, G). The intracellular solution was supplemented with cAMP to activate CFTR. The currents comprise a rapid sodium current followed by a more slowly opening calcium current. The charge was measured as the integral of the current and reflected the influx through the calcium channels. From the data we could conclude that the calcium current was not affected by CFTR inhibition (Figure 4F, G), suggesting a direct effect on the exocytotic machinery [21]. Interestingly, DIDS has earlier been demonstrated to reduce insulin exocytosis, an effect that has been coupled to intragranular $\mathrm{ClC} 3$ chloride channels and priming of the insulin granules [47], implying that CFTR can act by controlling ANO1 to influence priming and exocytosis. Depolarization-evoked exocytosis of primed granules is hypothesized to correspond to first phase insulin secretion [46], thus suggesting an important role of CFTR at this stage. Indeed, patients with $\mathrm{CF}$ exhibit reduced first phase insulin secretion $[9,15,16]$.

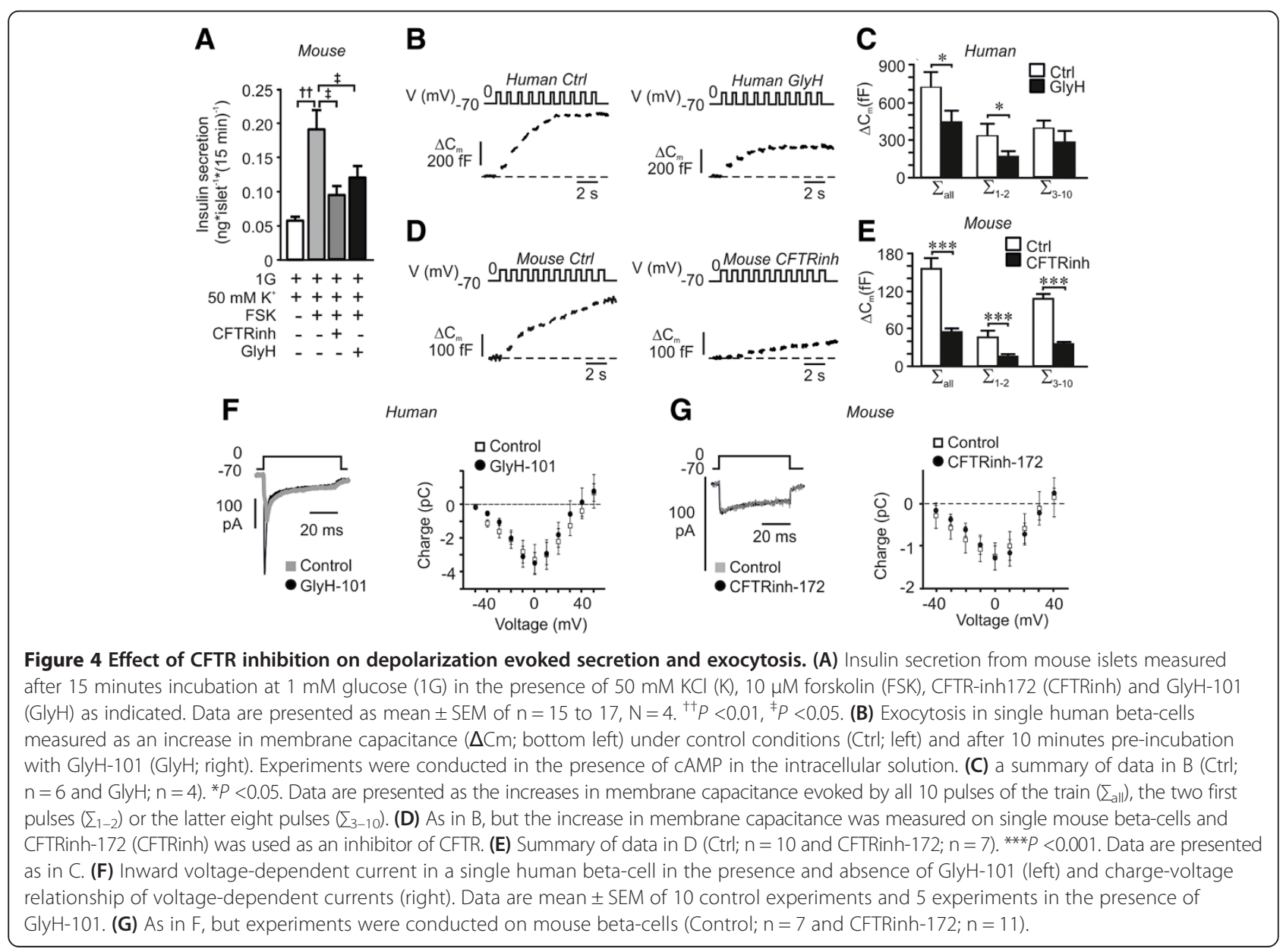


The above results prompted us to investigate granular docking using TEM, since docking of the granules to the plasma membrane is vital for exocytosis. Mouse islets were subject to incubation in $1 \mathrm{mM}$ glucose, $16.7 \mathrm{mM}$ glucose in the absence and/or presence of FSK and GlyH-101 prior to fixation (Figure 5A). We performed ultrastructural analysis and estimated the granule volume density per cell, $\mathrm{N}_{\mathrm{v}}$, and the surface density per cell, Ns, from the micrographs. $\mathrm{N}_{\mathrm{v}}$ and $\mathrm{N}_{\mathrm{s}}$ are proportional to the total number of granules and the number of docked granules, respectively. The total number of granules within the beta-cells was not changed between islets treated under the different conditions (Figure 5B). Glucose significantly increased the docked pool $\left(\mathrm{N}_{\mathrm{s}}\right)$ in agreement with previous observations that glucose enhances granule refilling and mobilization [48]. Addition of FSK caused a reduction in the number of docked granules, confirming earlier electrophysiological observations that mobilization is rate-limiting [49]. Finally, the docked pool of granules was significantly reduced in beta-cells incubated with GlyH-101 and FSK, as compared to FSK alone (Figure 5C).
Moreover, it is evident from the analysis that only the fraction of granules within $300 \mathrm{~nm}$ from the plasma membrane is affected by inhibition of CFTR (Figure 5D). This is in accordance with a role for CFTR in docking and priming of insulin granules.

CFTR has been shown to act through additional mechanisms, one being interaction with the SNARE-protein syntaxin 1A [50,51], a protein crucial for beta-cell granule docking and exocytosis [46]. To investigate the possibility that CFTR interacts with this SNARE-protein, we investigated the distribution of CFTR and syntaxin $1 \mathrm{~A}$, and found that CFTR was co-localized with syntaxin $1 \mathrm{~A}$ in the plasma membrane of human beta-cells $(86 \pm 2 \%$ colocalization, $n=39 ; \mathrm{N}=2$; Figure $5 \mathrm{E}$ ).

\section{Discussion}

Chloride channels play key roles in pancreatic beta-cells [17,52-54], but the exact identity of all chloride channels involved remains to be established. A previous study indicated that endocrine cells in the rat pancreas express the mRNA encoding CFTR [18]. Here we provide novel
A

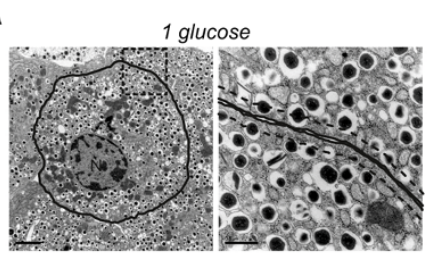

16.7 glucose and forskolin
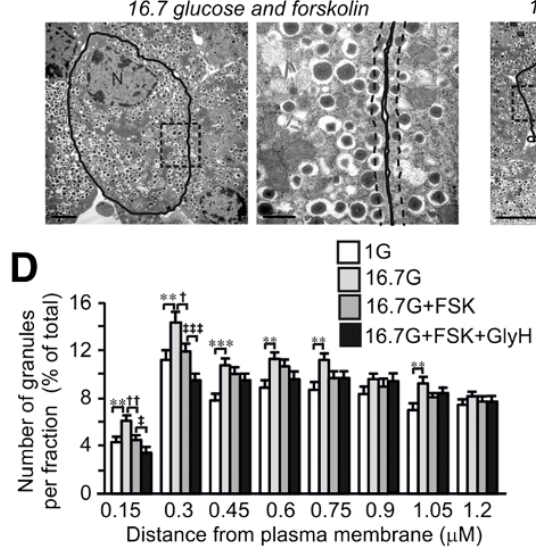

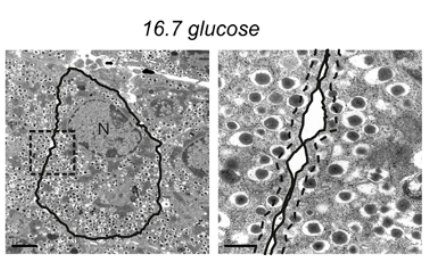

16.7 glucose, forskolin and $\mathrm{GlyH}-101$

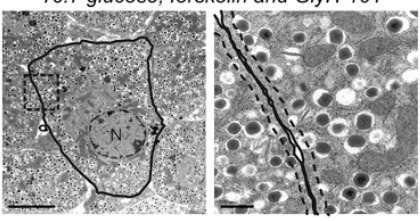

E
B

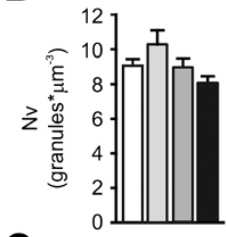

C

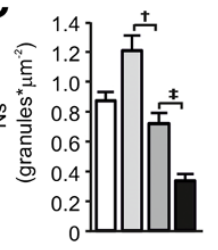

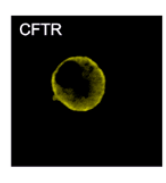
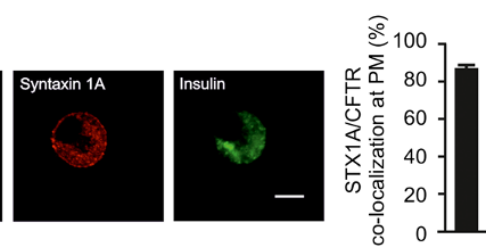

Figure $\mathbf{5}$ Consequences on ultrastructural parameters after CFTR inhibition. (A) Electron micrographs of a single beta-cell within an islet after incubation for one hour as indicated. The area within the dotted rectangle in the left image is highlighted to the right. The plasma membrane is indicated by a black solid line. The granules where defined as docked when the center of the granule was located within 150 nm from the plasma membrane (dashed line). $\mathrm{N}=$ nucleus. Scale bars: $2 \mu \mathrm{M}$ (left) and $0.5 \mu \mathrm{M}$ (right). (B) Bar graph of the total number of granules measured as volume density ( $\mathrm{N}_{v}$; granules* $\mu \mathrm{m}-3$ ) after incubation in $1 \mathrm{mM}$ glucose (1 G), $16.7 \mathrm{mM}$ glucose (16.7 G), $10 \mu \mathrm{M}$ forskolin (FSK) and 50 HM GlyH-101 (GlyH) as

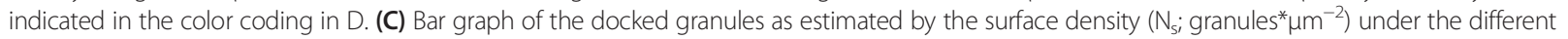
conditions as in D. (D) Relative distribution of granules at distance fractions from the PM. The distance at the $x$-axis is the upper border of each fraction. Color-coding for the different conditions is at the top right ( $\mathrm{n}=43$ to 45 cells, $\mathrm{N}=3$ animals per condition). For B-D, data are presented as mean \pm SEM. ${ }^{* *} P<0.0116 .7 \mathrm{G}$ vs $1 \mathrm{G}^{*}{ }^{* * *} P<0.00116 .7 \mathrm{G}$ vs $1 \mathrm{G}^{\dagger} P<0.05$ FSK vs $16.7 \mathrm{G}$ alone, ${ }^{+\dagger} P<0.01 \mathrm{FSK}$ vs $16.7 \mathrm{G}$ alone, ${ }^{\ddagger} P<0.05 \mathrm{GlyH}$ vs $16.7 \mathrm{G}$ and FSK alone, ${ }^{\neq \neq \ddagger} P<0.001 \mathrm{GlyH}$ vs $16.7 \mathrm{G}$ and FSK alone. (E) Localization of CFTR (yellow), syntaxin $1 \mathrm{~A}$ (red) and insulin (green) in fixed single human islet cells detected using confocal immunocytochemistry (left). A bar graph describing the measured co-localization in the plasma membrane is shown to the right. The images are from a representative cell out of 39 from two human donors. 
data adding CFTR to the list of chloride channels having important functions in human and mouse beta-cells [17,52-54], and suggest that CFTR acts upstream of ANO1 $[2,33,41]$ to control insulin secretion.

In a previous study, Kinard and Satin [17] measured an ATP- and cAMP-dependent chloride current in insulin secreting cells that could be activated under hypotonic conditions. The current was termed $\mathrm{I}_{\mathrm{Cl}, \text { islet }}$ and had similar properties in terms of size and reversal potential as the chloride current obtained here in the presence of glucose and FSK/GLP-1 (Figure 2). It was suggested [17] that the $\mathrm{I}_{\mathrm{Cl} \text {,islet }}$ contributes to cAMP-dependent depolarization at negative membrane potentials although the exact identity of the channel was not described. It has been suggested that the channel is a volume-regulated anion channel (VRAC; [55]), due to similarities with $\mathrm{I}_{\mathrm{Cl} \text {,islet }}$ in terms of activation and electrophysiological properties. Our focus was CFTR and we did not investigate the presence of a current sensitive to cell swelling. However, our data do not rule out the presence of VRAC. Whereas VRAC is suggested to enhance electrical activity, we hypothesize that the main function of CFTR/ANO1 is in the control of exocytosis. We confirm that activation of the ATP- and cAMP-dependent chloride current contributes to a small depolarization at potentials below the equilibrium potential for chloride, when the flux of chloride ions is outward from the cell comparable to the depolarization obtained by cAMP on electrical activity measured on whole islets $[56,57]$.

The measured current conductance in the presence of FSK varies among different batches of cells investigated and amounts between approximately 80 and $120 \mathrm{pS} / \mathrm{pF}$ and approximately 20 and $40 \mathrm{pS} / \mathrm{pF}$ in mouse beta-cells (Figures 2B, F and $3 \mathrm{~F}$ ) and human beta-cells (Figure 2B, E), respectively. Biological variation is common in studies on primary tissue and human primary tissue in particular. However, more importantly, the estimated CFTR conductance after blockade of other chloride-currents using DIDS or by blocking ANO1 becomes the same (13 pS/pF and 12 $\mathrm{pS} / \mathrm{pF}$, respectively), strongly supporting the presence of a CFTR conductance. Although small, the impact on insulin secretion is large, suggesting that CFTR has a function upstream of many other cAMP-activated processes involved in insulin secretion $[19,27,49,56,58]$.

We provide evidence suggesting that the main consequence of the cAMP-activated chloride current is unrelated to membrane depolarization (Figure 4A). More specifically our studies point to a role of CFTR and ANO1 in cAMP augmented calcium-dependent exocytosis. Indeed, both FSK- and GLP-1-enhanced, glucose-stimulated insulin secretion is reduced by CFTR-inhibitors. We observed that the inhibitors are more potent on GLP-1 than on FSK-stimulated secretion. This we mainly attribute to the fact that FSK increases cAMP to a higher level than
GLP-1 in islets (see, for example, [19]). The participation of CFTR in the exocytotic process is supported by the capacitance measurements showing that exocytosis is blocked by CFTR-inhibitors in both human and mouse beta-cells (Figure 4). Exocytosis is a calcium-dependent process and the reduced exocytotic response observed in the presence of the CFTR antagonists might be explained by a reduced calcium current [59], but this was proven not to be the case (Figure 4F, G). Based upon our observations from insulin secretion and electrophysiological ramp-protocol measurements we instead hypothesize that CFTR through ANO1 act directly on exocytosis. Indeed, we found CFTR to co-localize with the SNARE-protein syntaxin 1A (Figure 5E) as demonstrated in other tissues [50,51]. This suggests that CFTR, as syntaxin $1 \mathrm{~A}$, is part of the exocytotic machinery.

From our novel results we suggest that CFTR plays a key role in priming of the insulin granules; this is evident from the capacitance measurements and the electron micrographic data. The increase in membrane capacitance evoked by a train of membrane depolarizations initiates exocytosis of release-ready (primed) granules by the first two depolarizations, whereas the latter depolarizations enable granules within a larger reserve pool to be released [46]. Our data demonstrate a pronounced reduction in exocytosis evoked during the two first depolarizations (Figure 4B-E). Hence, CFTR can be suggested to have its main function in the priming of insulin granules. Moreover, the ultrastructural analysis revealed that the number of granules in close vicinity to the plasma membrane $(<300 \mathrm{~nm})$ was reduced after CFTR inhibition (Figure 5D). The exact molecular mechanism by which CFTR contributes to granular priming is hitherto unknown. Interestingly, DIDS has earlier been demonstrated to reduce insulin exocytosis, an effect that has been coupled with intragranular $\mathrm{ClC} 3$ chloride channels and priming of the insulin granules [47]. A role for $\mathrm{ClC} 3$ in insulin granular priming and exocytosis has also been proven by knock-out animals [54]. Here we demonstrate that CFTR inhibition reduces exocytosis to the same extent as has earlier been demonstrated for DIDS [47] and removal of ClC3 [54]. As DIDS is a chloride channel blocker inhibiting the current through most chloride channels except for CFTR, the ANO1 current is likely reduced by this treatment (compare Figures 2F and 3F). Our insulin secretion measurements and chloride current measurements suggest that CFTR acts on ANO1. The mechanisms by which ANO1 is regulated by CFTR is yet to be investigated, but the small influx of chloride through CFTR seems to have some function since the ANO1 current was inhibited by the CFTR-specific open-channel blocker Gly-H 101 (Figure 3F). The fact that ANO1 is calcium activated [41] is consistent with a role of this channel in exocytosis. It can be argued that the increase in cAMP will 
enhance the voltage-dependent calcium-influx [58] and thereby increase the ANO1 current and insulin secretion. This process can most likely occur in parallel with the cAMP-dependent regulation of ANO1 via CFTR as demonstrated here. Our data, however, demonstrate a role for CFTR in regulating insulin secretion through a direct effect on exocytosis.

\section{Conclusions}

As illustrated in the model in Figure 6, we propose participation of CFTR, ANO1 and $\mathrm{ClC} 3$ in the same process and suggest that ion-fluxes through these ion channels together contribute to improved beta-cell exocytosis and priming. We hypothesize that cAMP activates CFTR, in addition to parallel activation of proteins already known to be important for insulin granule exocytosis. These include PKA that is stimulating calcium influx [58] and granular mobilization [49] and Epac2, which are involved in granular priming [19]. Epac2 is in complex with SUR1 and the granular ClC3 chloride channel $[19,54]$. We postulate that CFTR via ANO1 provides granular $\mathrm{ClC} 3$ chloride channels with chloride ions necessary to improve cAMP-dependent granular priming, exocytosis and secretion. This is possible since the flux of chloride ions changes during an action potential and is inward above the equilibrium potential for chloride. Thus, the direction of the chloride flux is into the cell at potentials needed to initiate exocytosis (above approximately $-20 \mathrm{mV}$ ).

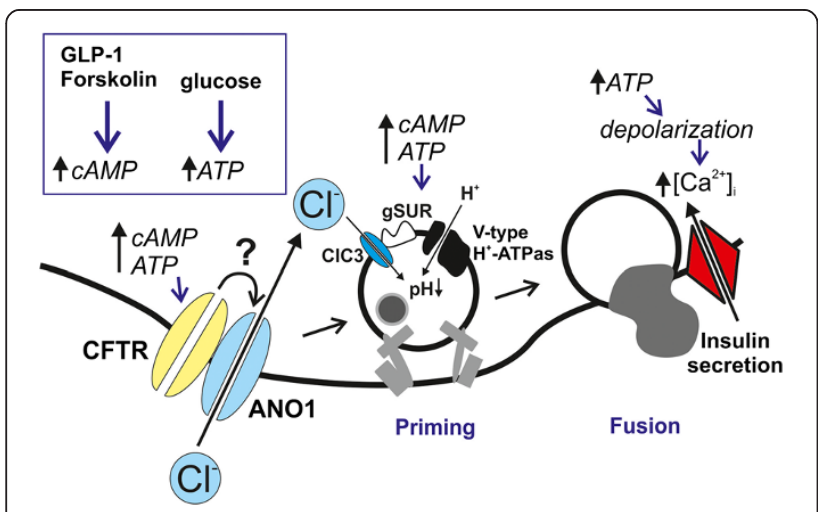

Figure 6 Model describing a possible involvement of CFTR in beta-cell granular priming and exocytosis. High glucose increases intracellular ATP leading to depolarization and influx of intracellular calcium triggering exocytosis. GLP-1 and forskolin (FSK) increase intracellular CAMP, which, together with the increase in ATP, enhance the priming of insulin granules, a process that involves influx of chloride into the granules through the intragranular $\mathrm{CIC} 3$ channels. Our data indicate that CAMP and ATP in parallel activate CFTR. We suggest that CFTR through a still unknown mechanism regulates $\mathrm{ANO1}$ and hypothesize that the influx of chloride through ANO1 supplies the intragranular CIC3 channel and thereby enhances granular priming. CFTR, Cystic Fibrosis Transmembrane conductance regulator; ANO1, Anoctamin 1 chloride channel; gSUR, granular sulfonylurea receptor; $\mathrm{Ca}^{2+}$, calcium.
Depolarization-evoked exocytosis of primed granules is hypothesized to correspond to the first phase insulin secretion [46], suggesting an important role for CFTR at this stage. Indeed, many CF patients suffer from postprandial hyperglycemia although they have normal fasting plasma glucose levels indicating that the beta-cells fail to respond upon increased insulin demand. For these patients, impaired insulin secretion is mostly apparent during the first phase, strongly indicating a defect at the level of the pancreatic beta-cell $[9,14-16]$. The impaired insulin secretion has been suggested to be due to severe exocrine tissue damage destroying the beta-cells $[4,10,11,13,15]$, but others have indicated direct effects on beta-cell function $[9,15,16,60,61]$. Indeed, reduced or absent acute insulin response to glucose in patients with CFRD was recently shown to be compensated by pharmacological CFTR potentiation [16]. Here we provide a likely explanation to the clinical observations supporting an effect on beta-cell function. We demonstrate for the first time that CFTR has a role at the cellular level, in both human and mouse beta-cells, by regulating insulin secretion. Specifically, we provide evidence that interference with CFTR affects cAMP-dependent rapid exocytosis of primed granules important for first phase insulin release.

\begin{abstract}
Abbreviations
ABC transporters: ATP-binding cassette-transporters; ANO1: Anoctamin 1 chloride channel; BMI: Body Mass Index; CF: Cystic fibrosis; CFRD: Cystic fibrosis-related diabetes; CFTR: Cystic fibrosis transmembrane conductance regulator; Epac2: Exchange protein directly activated by CAMP 2; FSK: Forskolin; gSUR: granular Sulfonylura receptor; MSD: Membrane spanning domain; NBD: Nucleotide binding domain; $N_{s}$ : surface density of granules; $\mathrm{N}_{\mathrm{v}}$ : volume density of granules; RIA: Radioimmunoassay; SNARE: Soluble NSF attachment protein receptor; SUR: Sulfonylurea receptor; TEM: Transmission electron microscopy; VRAC: Volume regulated anion channel.
\end{abstract}

\section{Competing interests}

The authors declare they have no competing interests.

\section{Authors' contribution}

$\mathrm{AE}$ and LE designed the project, performed research, analyzed the data and wrote the paper. JLSE performed research, analyzed data and reviewed and revised the manuscript. AW analyzed data and reviewed and revised the manuscript. MF-T designed the project and wrote the paper. All authors read and approved the final manuscript.

\section{Acknowledgements}

We thank Professors C. Wollheim (Lund University, Sweden and University of Geneva, Switzerland) and S. Cushman (Lund University, Sweden and NIH, USA) for critical reading of the manuscript; Professor A.S. Verkman (UCSF, USA) for kindly providing TM16Ainh-AO1; B.M. Nilsson, A.M.V. Ramsay and R. Wallén (Lund University, Sweden) for technical assistance; and the LUDC Human Tissue Laboratory (Lund University, Sweden) and The Nordic Network for Islet Transplantation for providing human islets (Uppsala University, Sweden).

This work was supported by the Swedish Research Council through project grant (L.E), Linneus grant (LUDC) and Strategic Research grant (Exodiab), the Knut and Alice Wallenberg Foundation, the European Union (EU-FP-7, BetaBat), The Diabetes Wellness Foundation (LE), The Swedish Diabetes Foundation (L.E.), Albert Påhlsson Foundation (L.E.) and Region Skåne (ALF; L. E.). MFT. is supported by Karolinska Institutet, Stockholm, Sweden and a VINNMER fellowship from VINNOVA, Sweden. LE is a senior researcher at the Swedish Research Council. 


\section{Author details}

${ }^{1}$ Unit of Islet Cell Exocytosis, Lund University Diabetes Centre, Department Clinical Sciences in Malmö, Lund University, Clinical Research Centre, SUS Malmö, Jan Waldenströms gata 35, SE 20502 Malmö, Sweden. ${ }^{2}$ Center for Infectious Medicine, Department of Medicine Huddinge, Karolinska Institutet, Stockholm, Sweden.

Received: 9 December 2013 Accepted: 10 April 2014 Published: 28 May 2014

\section{References}

1. Sheppard DN, Welsh MJ: Structure and function of the CFTR chloride channel. Physiol Rev 1999, 79:S23-S45.

2. Schwiebert EM, Benos DJ, Egan ME, Stutts MJ, Guggino WB: CFTR is a conductance regulator as well as a chloride channel. Physiol Rev 1999 79:S145-S166

3. Rowntree RK, Harris A: The phenotypic consequences of CFTR mutations. Ann Hum Genet 2003, 67:471-485.

4. Brennan AL, Geddes DM, Gyi KM, Baker EH: Clinical importance of cystic fibrosis-related diabetes. J Cyst Fibros 2004, 3:209-222

5. de Valk H, van der Graaf E: Cystic Fibrosis-Related Diabetes in adults: where can we go from here? Rev Diabet Stud 2007, 4:6-12.

6. Dobson L, Sheldon CD, Hattersley AT: Understanding cystic-fibrosis-related diabetes: best thought of as insulin deficiency? J R Soc Med 2004 97:26-35.

7. Moran A, Dunitz J, Nathan B, Saeed A, Holme B, Thomas W: Cystic fibrosis-related diabetes: current trends in prevalence, incidence, and mortality. Diabetes Care 2009, 32:1626-1631.

8. Moran A, Diem P, Klein DJ, Levitt MD, Robertson RP: Pancreatic endocrine function in cystic fibrosis. J Pediatr 1991, 118:715-723.

9. Kelly A, Moran A: Update on cystic fibrosis-related diabetes. J Cyst Fibros 2013, 12:318-331.

10. Abdul-Karim FW, Dahms BB, Velasco ME, Rodman HM: Islets of Langerhans in adolescents and adults with cystic fibrosis. A quantitative study. Arch Pathol Lab Med 1986, 110:602-606.

11. Iannucci A, Mukai K, Johnson D, Burke B: Endocrine pancreas in cystic fibrosis: an immunohistochemical study. Hum Pathol 1984, 15:278-284.

12. Löhr M, Goertchen P, Nizze H, Gould NS, Gould VE, Oberholzer M, Heitz PU, Klöppel G: Cystic fibrosis associated islet changes may provide a basis for diabetes. An immunocytochemical and morphometrical study. Virchows Arch A Pathol Anat Histopathol 1989, 414:179-185.

13. Soejima $\mathrm{K}$, Landing $\mathrm{BH}$ : Pancreatic islets in older patients with cystic fibrosis with and without diabetes mellitus: morphometric and immunocytologic studies. Pediatr Pathol 1986, 6:25-46.

14. Lanng S: Glucose intolerance in cystic fibrosis patients. Paediatr Respir Rev 2001, 2:253-259.

15. Moran A, Becker D, Casella SJ, Gottlieb PA, Kirkman MS, Marshall BC, Slovis B: Epidemiology, pathophysiology, and prognostic implications of cystic fibrosis-related diabetes: a technical review. Diabetes Care 2010, 33:2677-2683

16. Bellin MD, Laguna T, Leschyshyn J, Regelmann W, Dunitz J, Billings J, Moran A: Insulin secretion improves in cystic fibrosis following ivacaftor correction of CFTR: a small pilot study. Pediatr Diabetes 2013, 14:417-421.

17. Kinard TA, Satin LS: An ATP-sensitive Cl- channel current that is activated by cell swelling, CAMP, and glyburide in insulin-secreting cells. Diabetes 1995, 44:1461-1466.

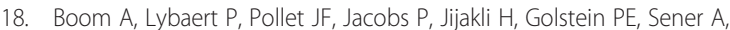
Malaisse WJ, Beauwens R: Expression and localization of cystic fibrosis transmembrane conductance regulator in the rat endocrine pancreas. Endocrine 2007, 32:197-205.

19. Eliasson L, Ma X, Renström E, Barg S, Berggren PO, Galvanovskis J, Gromada J, Jing X, Lundquist I, Salehi A, Sewing S, Rorsman P: SUR1 regulates PKA-independent CAMP-induced granule priming in mouse pancreatic B-cells. J Gen Physiol 2003, 121:181-197.

20. Esguerra JL, Bolmeson C, Cilio CM, Eliasson L: Differential glucose-regulation of microRNAs in pancreatic islets of non-obese type 2 diabetes model Goto-Kakizaki rat. PLoS One 2011, 6:e18613.

21. Vikman J, Ma X, Hockerman GH, Rorsman P, Eliasson L: Antibody inhibition of synaptosomal protein of $25 \mathrm{kDa}$ (SNAP-25) and syntaxin 1 reduces rapid exocytosis in insulin-secreting cells. $J$ Mol Endocrinol 2006 36:503-515.
22. De Marinis $Y Z$, Salehi A, Ward CE, Zhang Q, Abdulkader F, Bengtsson M, Braha O, Braun M, Ramracheya R, Amisten S, Habib AM, Moritoh Y, Zhang E, Reimann F, Rosengren AH, Shibasaki T, Gribble F, Renström E, Seino S, Eliasson L, Rorsman P: GLP-1 inhibits and adrenaline stimulates glucagon release by differential modulation of $\mathrm{N}$ - and L-type Ca2+ channel-dependent exocytosis. Cell Metab 2010, 11:543-553.

23. Caci E, Caputo A, Hinzpeter A, Arous N, Fanen P, Sonawane N, Verkman AS, Ravazzolo R, Zegarra-Moran O, Galietta L: Evidence for direct CFTR inhibition by CFTR(inh)-172 based on Arg347 mutagenesis. Biochem J 2008, 413:135-142.

24. Muanprasat C, Sonawane ND, Salinas D, Taddei A, Galietta LJ, Verkman AS: Discovery of glycine hydrazide pore-occluding CFTR inhibitors: mechanism, structure-activity analysis, and in vivo efficacy. J Gen Physiol 2004, 124:125-137.

25. Akesson B, Henningsson $R$, Salehi A, Lundquist I: Islet constitutive nitric oxide synthase and glucose regulation of insulin release in mice. J Endocrinol 1999, 163:39-48.

26. Andersson SA, Pedersen MG, Vikman J, Eliasson L: Glucose-dependent docking and SNARE protein-mediated exocytosis in mouse pancreatic alpha-cell. Pflugers Arch 2011, 462:443-454.

27. Tian G, Sandler S, Gylfe E, Tengholm A: Glucose- and hormone-induced cAMP oscillations in alpha- and beta-cells within intact pancreatic islets. Diabetes 2011, 60:1535-1543.

28. Tian G, Sol ER, Xu A, Tengholm A: Prolonged exposure to palmitate deteriorates glucose-induced CAMP generation and pulsatile insulin secretion. Diabetologia 2013, S56:S194.

29. Cabrera O, Berman DM, Kenyon NS, Ricordi C, Berggren PO, Caicedo A: The unique cytoarchitecture of human pancreatic islets has implications for islet cell function. Proc Natl Acad Sci U S A 2006, 103:2334-2339.

30. Huypens P, Ling Z, Pipeleers D, Schuit F: Glucagon receptors on human islet cells contribute to glucose competence of insulin release. Diabetologia 2000, 43:1012-1019.

31. Seino S: Cell signalling in insulin secretion: the molecular targets of ATP, cAMP and sulfonylurea. Diabetologia 2012, 55:2096-2108.

32. Gopel SO, Kanno T, Barg S, Weng XG, Gromada J, Rorsman P: Regulation of glucagon release in mouse -cells by KATP channels and inactivation of TTX-sensitive Na + channels. J Physiol 2000, 528:509-520.

33. Gabriel SE, Clarke LL, Boucher RC, Stutts MJ: CFTR and outward rectifying chloride channels are distinct proteins with a regulatory relationship. Nature 1993, 363:263-268.

34. Cliff WH, Schoumacher RA, Frizzell RA: cAMP-activated Cl channels in CFTR-transfected cystic fibrosis pancreatic epithelial cells. Am J Physiol 1992, 262:C1154-C1160.

35. Schultz BD, Singh AK, Devor DC, Bridges RJ: Pharmacology of CFTR chloride channel activity. Physiol Rev 1999, 79:S109-S144.

36. Gojkovic-Bukarica L, Hambrock A, Loffler-Walz C, Quast U, Russ U: Mg2+ sensitizes KATP channels to inhibition by DIDS: dependence on the sulphonylurea receptor subunit. Br J Pharmacol 2002, 137:429-440.

37. Sheppard DN, Welsh MJ: Effect of ATP-sensitive $\mathrm{K}+$ channel regulators on cystic fibrosis transmembrane conductance regulator chloride currents. J Gen Physiol 1992, 100:573-591.

38. Henquin JC, Dufrane D, Nenquin M: Nutrient control of insulin secretion in isolated normal human islets. Diabetes 2006, 55:3470-3477.

39. Ishiyama N, Ravier MA, Henquin JC: Dual mechanism of the potentiation by glucose of insulin secretion induced by arginine and tolbutamide in mouse islets. Am J Physiol Endocrinol Metab 2006, 290:E540-E549.

40. Kunzelmann K, Tian Y, Martins JR, Faria D, Kongsuphol P, Ousingsawat J, Wolf $L$, Schreiber R: Airway epithelial cells-functional links between CFTR and anoctamin dependent $\mathrm{Cl}$ - secretion. Int J Biochem Cell Biol 2012, 44:1897-1900.

41. Winpenny JP, Gray MA: The anoctamin (TMEM16) gene family: calciumactivated chloride channels come of age. Exp Physiol 2012, 97:175-176.

42. Malaisse WJ, Virreira M, Zhang Y, Crutzen R, Bulur N, Lybaert P, Golstein PE, Sener A, Beauwens R: Role of anoctamin 1 (TMEM16A) as a volume regulated anion channel in insulin-producing cells. Diabetologia 2012, 55:S204.

43. Mahdi T, Hänzelmann S, Salehi A, Muhammed SJ, Reinbothe TM, Tang Y, Axelsson AS, Zhou Y, Jing X, Almgren P, Krus U, Taneera J, Blom AM, Lyssenko V, Esguerra JL, Hansson O, Eliasson L, Derry J, Zhang E, Wollheim CB, Groop L, Renström E, Rosengren AH: Secreted frizzled-related protein 4 reduces insulin secretion and is overexpressed in type 2 diabetes. Cell Metab 2012, 16:625-633. 
44. Namkung W, Phuan PW, Verkman AS: TMEM16A inhibitors reveal TMEM16A as a minor component of calcium-activated chloride channel conductance in airway and intestinal epithelial cells. J Biol Chem 2011, 286:2365-2374.

45. Ashcroft FM, Rorsman P: Diabetes mellitus and the beta cell: the last ten years. Cell 2012, 148:1160-1171.

46. Eliasson L, Abdulkader F, Braun M, Galvanovskis J, Hoppa MB, Rorsman P: Novel aspects of the molecular mechanisms controlling insulin secretion. J Physiol 2008, 586:3313-3324.

47. Barg S, Huang P, Eliasson L, Nelson DJ, Obermuller S, Rorsman P, Thevenod $\mathrm{F}$, Renstrom E: Priming of insulin granules for exocytosis by granular $\mathrm{Cl}(-)$ uptake and acidification. J Cell Sci 2001, 114:2145-2154.

48. Eliasson L, Renstrom E, Ding WG, Proks P, Rorsman P: Rapid ATP-dependent priming of secretory granules precedes $\mathrm{Ca}(2+)$-induced exocytosis in mouse pancreatic B-cells. J Physiol 1997, 503:399-412

49. Renstrom E, Eliasson L, Rorsman P: Protein kinase A-dependent and independent stimulation of exocytosis by CAMP in mouse pancreatic B-cells. J Physio/ 1997, 502:105-118.

50. Ganeshan R, Di A, Nelson DJ, Quick MW, Kirk KL: The interaction between syntaxin $1 \mathrm{~A}$ and cystic fibrosis transmembrane conductance regulator $\mathrm{Cl}$ - channels is mechanistically distinct from syntaxin 1A-SNARE interactions. J Biol Chem 2003, 278:2876-2885.

51. Naren AP, Nelson DJ, Xie W, Jovov B, Pevsner J, Bennett MK, Benos DJ, Quick MW, Kirk KL: Regulation of CFTR chloride channels by syntaxin and Munc18 isoforms. Nature 1997, 390:302-305.

52. Best L: Glucose-induced electrical activity in rat pancreatic beta-cells: dependence on intracellular chloride concentration. J Physiol 2005, 568:137-144.

53. Braun M, Ramracheya R, Bengtsson M, Clark A, Walker JN, Johnson PR, Rorsman P: Gamma-aminobutyric acid (GABA) is an autocrine excitatory transmitter in human pancreatic beta-cells. Diabetes 2010, 59:1694-1701.

54. Li DQ, Jing X, Salehi A, Collins SC, Hoppa MB, Rosengren AH, Zhang E, Lundquist I, Olofsson CS, Mörgelin M, Eliasson L, Rorsman P, Renström E: Suppression of sulfonylurea- and glucose-induced insulin secretion in vitro and in vivo in mice lacking the chloride transport protein $\mathrm{ClC}-3$. Cell Metab 2009, 10:309-315.

55. Best $L$, Brown PD, Sener A, Malaisse WJ: Electrical activity in pancreatic islet cells: the VRAC hypothesis. Islets 2010, 2:59-64.

56. Henquin JC, Meissner HP: Dibutyryl cyclic AMP triggers Ca2+ influx and Ca2 + -dependent electrical activity in pancreatic B cells. Biochem Biophys Res Commun 1983, 112:614-620.

57. Ikeuchi M, Cook DL: Glucagon and forskolin have dual effects upon islet cell electrical activity. Life Sci 1984, 35:685-691.

58. Ammala C, Ashcroft FM, Rorsman P: Calcium-independent potentiation of insulin release by cyclic AMP in single beta-cells. Nature 1993, 363:356-358.

59. Ammala C, Eliasson L, Bokvist K, Larsson O, Ashcroft FM, Rorsman P: Exocytosis elicited by action potentials and voltage-clamp calcium currents in individual mouse pancreatic B-cells. J Physiol 1993, 472:665-688.

60. Battezzati A, Mari A, Zazzeron L, Alicandro G, Claut L, Battezzati PM, Colombo $C$ : Identification of insulin secretory defects and insulin resistance during oral glucose tolerance test in a cohort of cystic fibrosis patients. Eur J Endocrinol 2011, 165:69-76.

61. Olivier AK, Yi Y, Sun X, Sui H, Liang B, Hu S, Xie W, Fisher JT, Keiser NW, Lei D, Zhou W, Yan Z, Li G, Evans TI, Meyerholz DK, Wang K, Stewart ZA, Norris AW, Engelhardt JF: Abnormal endocrine pancreas function at birth in cystic fibrosis ferrets. J Clin Invest 2012, 122:3755-3768.

10.1186/1741-7015-12-87

Cite this article as: Edlund et al.: CFTR and Anoctamin 1 (ANO1)

contribute to CAMP amplified exocytosis and insulin secretion in human and murine pancreatic beta-cells. BMC Medicine 2014, 12:87

\section{Submit your next manuscript to BioMed Central and take full advantage of:}

- Convenient online submission

- Thorough peer review

- No space constraints or color figure charges

- Immediate publication on acceptance

- Inclusion in PubMed, CAS, Scopus and Google Scholar

- Research which is freely available for redistribution 